\title{
Language editor's note
}

The articles in this special issue of Temenos focusing on religious education / religion education in Nordic schools raises several tricky points of terminology, some relating to the academic discipline of the study of religions - Religionswissenschaft (however it may be termed in each country and each language), and others to specifics of the national school systems.

It is difficult to fix upon a single consensus English term for the academic study of religions, whether as a subject (a unit of curricular organization), or a university or college department (a unit of human and material resource management), or a discipline (a research field). Each of the potential terms tends to carry with it the implication of a particular ideological interpretation. Within the Nordic languages (both Scandinavian and Finnish), the 'domestic' name is often a cognate or a calque of the German term Religionswissenschaft, which unfortunately does not translate straightforwardly into English because of the fairly strict English distinction between science and scholarship, both of which are comfortably covered by Wissenschaft and its equivalents in other languages. For this volume, the guest editors have chosen to use the term study of religions, with the aim of emphasizing a maximal distancing from any confessional orientation.

Within national school systems (as distinct from higher educational institutions such as universities or colleges), a widely-used term for the school subject addressing religion is religious education, abbreviated RE. The authors of the articles in this issue of Temenos frequently make use of a distinction, however, between religious education and religion education, where the former is seen as typically having a more confessional character and the latter as striving for nonconfessional objectivity. Somewhat confusingly, the acronym RE may be used for either or both of these differentiated concepts. Within the history of each Nordic country, moreover, the name of the school subject in the national languages has frequently been amended, often with a deliberate ideological intent; some of these renaming-strategy exercises are discussed in the individual articles.

For the school systems being discussed, the most important point for international readers is to recognize that these countries all share a distinctive Nordic model, in which the nine or so years of compulsory schooling from approximately 7 to approximately 16 years of age are organized within a single integrated institutional framework; in other words, the threshold between primary / elementary schooling and lower-secondary schooling, which in many systems internationally is a major hiatus, is minimized in 
the Nordic countries as a system-internal transition. This is not merely an institutional nuance, but reflects a distinctive philosophy of that phase of schooling which almost all citizens are expected to share. Once again, it is extremely difficult to find a consensus term in English for this concept - and the various Nordic countries also use semantically different terms within their own languages for the integrated institution. Here our preferred editorial solution is to keep the source-language term for each country, its very 'exoticness' hopefully acting as a reminder to non-Nordic readers that Nordic schools are, indeed, different.

Keith Battarbee

Language Editor, Temenos 